\title{
Banking Efficiency, Law Enforcement and Chinese Provincial Economic Growth
}

\author{
Yu XIA \\ ${ }^{1}$ Department of Law, School of Politics \& Law and Public \\ Administration, Hubei University, Wuhan, China
}

\author{
Xianliang Tian \\ Department of Finance, School of Business, Hubei University, \\ Wuhan, China
}

\begin{abstract}
The body of literature about institutes' efficiency is mainly fallen into the field of microeconomics, even though in theory, the efficiency could be related to economic growth. This paper tries to fill this gap by examining empirically the relationship between banking sectors' efficiency and provincial economic grow in China, while the role of law enforcement is also investigated. We construct a variable which proxies for the efficiency of Chinese banking sector as a whole. When putting it into the classical growth estimation, the results show that there exists strong positive relationship between banking efficiency and Chinese provincial economic growth. In addition, we find that in regions where law enforcement is more effective, the effect of banking system on economic growth is more salient.
\end{abstract}

Keywords-Banking System, Law Enforcement, Economic Growth, Cost Efficiency

\section{Introduction}

The research in the relationship between economic growth and banking sector development can be dated back as early as Schumpeter (1934), and Goldsmith (1969). Since then, this subject has earned extensive attentions in economic researches. The empirical analysis in the relationship between these two variables has been well documented. Most regression outcomes show that banking system plays an important role in promoting the development of regional economy. For instance, based on cross-nation data, Rajan \& Zingales(1998) concludes that in a foreign-investment-dependent nation, the higher the banking system's efficiency, the faster the development of its firms is. King \& Levine (1993a), employing historical data of nearly 80 countries, argued that high positive relevance between bank's development and economic growth did exist. They further inferred that bank's development could facilitate economic growth by increasing the rate of capital accumulation and economy efficiency. Referring to current domestic literature, Tan Ruyong(1999), Wang Guosong(2001) \& Rao Huacun(2001) all identified the causal relationship between banking and economic growth through empirical analysis.

In most empirical literature, the banking system's state of development is usually measured by the scale of banking system or the amount of capital intermediated by banks. To be specific, the indicators used to depict the development of banking system include the ratio between liquid liabilities of the banking system and GDP (King \& Levine (1993b)), the proportion of bank branches to the regional resident population (Ferri \& Mattesini, (1997)), the ratio between domestic credit and GDP (Rajan \& Zingales (1998)), etc. However, these measurements have some inherent flaws in capturing the relationship between banking system development and economic growth, that is, they mainly focus on the effect of bank on stimulating capital accumulation. The theory of financial intermediary developed since 1980's shows that another important function of commercial bank is to discriminate optimal borrowers, alleviate the problem of information asymmetry in the financial market, and hence stimulate the optimal allocation of capital in the result of promoting economic growth (Diamond (1984), Stiglitz \& Weiss (1988)). However, current literature seldom investigates such kind of role of banks on the economic growth with an empirical view. Levine (1997) points out that, the only measuring of financial development which seeks to capture banks' allocative aspects is the share of financing granted to the private sector as a proportion of the overall amount of financing injected to the economy. This approach is based on the premise that the private sector is more efficient than the public one. Obviously, the hypothesis itself is prone to be doubted for various kinds of reasons. Besides, we should notice that, for many developing countries, the share of credit granted to the public sector is mainly the outcome of government intervention rather than the discretionary allocative decisions of banks. In this regard, this measurement itself can't efficaciously capture the banks' ability to improve the efficiency of credit allocation, taking account of political factors.

In this paper, we attempt to construct an indicator that is able to reflect the allocative efficiency of banking systems based on micro-efficiency of individual banks, and then investigate the relationship between this indicator and the rate of Chinese economic growth. In general, the higher individual banks' ability to identify the quality borrowers and optimize the allocation of financial resources, the more efficient the regional banking system is. Hence, by analyzing the relationship between this indicator and regional economic growth rate, we might probably substantiate that the bank's ability to identify quality borrowers indeed plays a role in facilitating economic growth. Utilizing this logic, we first calculate the cost efficiency of the 14 biggest commercial banks of China, and then we construct the banking system's efficiency index based on the weighted average of the bank's individual cost efficiency in each region. After putting this index into the growth regression model, we find that, in China, the banking system's efficiency indeed exert a salient positive influence upon the regional growth rate; and therefore the empirical results demonstrate that the bank's economy- 
facilitating role can also be realized though their screening ability. In addition, we find that in regions where law enforcement is more efficient, the effect of banking system on economic growth is more salient.

\section{Research Methods}

The general model used in empirical analysis of economic growth is presented as the following (Mankiw et al (1992)):

$$
y_{t}-y_{t-1}=\varphi y_{t-1}+\chi k_{t-1}+\psi S_{t-1}+\varepsilon_{t}
$$

Where $y_{t}$ denotes logarithm of GDP per capita over period $\mathrm{t}$ in one country (region); $k_{t-1}$ is the logarithm of the ratio of banking credit granted to the country (region) and its GDP over the period t-1; $S_{t-1}$, considered as long-term potential determinants of economic growth, is a vector containing other financial and control variables in logarithmic form. $\varepsilon_{t}$ is the random error term. With regard to the explanation of coefficients in formula (1), if $\varphi<0$, then it shows the existence of conditional convergence. $\chi$ describes the effect of bank's credit supply on the economic growth, if the estimation result is $\chi>0$, it shows that banking system could promote economic growth through the channel of capital accumulation.

$K_{t}$ is defined as the ratio between bank system's credit scale and GDP in one country (region). An important hypothesis in this paper is that, for a given credit size, varied efficiency of the banking system may lead to different contribution to the economic growth. Therefore, we construct an effective credit size index $\stackrel{\Lambda}{K}_{t}$ to depict the impact of banking system's efficiency on economic growth, the specification of $\stackrel{\Lambda}{K}_{t}$ can be formulated as the following:

$$
\stackrel{\Lambda}{K_{t}}=K_{t}\left(1-\mu_{t}\right)^{\rho}
$$

Here, we use parameter $\mu_{t}\left(0 \leq \mu_{t} \leq 1\right)$ to quantify the inefficiency of banking system. The bigger the value of $\mu_{t}$, the lower the efficiency of banking system in one country (region), and the lower the ability the bank system has in that country(region) to screen borrowers and optimally allocate capital. Under this situation, a given capital size, $K_{t}$, can only

$$
\Lambda
$$

parallel to the smaller size of effective credit, $K_{t}$, considering their contributions to economic growth. Therefore, in this paper, both the efficiency of banking system and the whole credit scale issued by it have the joint influence upon the growth rate of a country (region). Specifically, when bank system's efficiency is extremely low, i.e. $\mu_{t}$ is close to one, the contribution of loans to economic growth will come close to zero. Finally, $\rho$ depicts the extent to which this inefficiency exerts on economic growth.
In the following, we substitute $K_{t}$ for $\stackrel{\Lambda}{K}_{t}$, yielding the regression equation as below:

$$
y_{t}-y_{t-1}=\varphi y_{t-1}+\chi k_{t-1}+\stackrel{\Lambda}{\rho} \ln \left(1-\mu_{t-1}\right)+\psi S_{t-1}+\varepsilon_{t}
$$

$\Lambda$

Herein, $\rho=\rho \chi$. If the diagnostic result shows that $\chi$ is $\Lambda$

positive, and $\rho=0$, it means that the role of banking system on economic growth is mainly capital accumulative and the effect of credit allocation is not significant. Nevertheless, if $\Lambda$

both $\chi$ and $\rho$ are significantly non-zero, we then can come to the point that the effect of credit allocation on economic growth could not be excluded.

\section{An Index Measuring Banking System’s Efficiency}

\section{A The estimation of technical efficiency of commercial banks}

There exist two kinds of concepts of technical microefficiency in current literature: cost efficiency and profit efficiency. In this paper, we choose the concept of cost efficiency to measure technical efficiency of individual bank for the facts that a bank's ability to make profits may not coincide with its ability to screen best borrowers. In some cases, banks can even get admirable profits through the manipulation of prices, which is especially applicable in Chinese banking sector for its less competitive market structure.

The techniques applied when estimating an entity's technical efficiency usually involve DEA technique, also known as non-parametric techniques and stochastic frontier technique, one of the techniques of parametric estimation ${ }^{1}$. We prefer a parametric technique here to make best of its advantage of allowing one to conduct hypothesis test; besides, the estimation of micro-efficiency with this method is unbiased. In what following, we will choose stochastic frontier technique to estimate technical efficiency of individual banks.

Berger (1993) gives the general formula for cost efficiency estimation under parametric techniques:

$$
R C=C(Q, W) \cdot U
$$

Here, $R C$ represents real cost, $C(Q, W)$ is theoretically minimal cost. $U \in[1, \infty)$ reflects the degree of cost squander of commercial banks, reciprocal of which denotes the value of cost efficiency. $Q=\left(Q_{1}, Q_{2} \cdots\right)$ is a vector of quantities for various outputs. And $W=\left(W_{1}, W_{2}, \cdots\right)$ is a vector for prices of inputs.

Take the logarithm of equation (4), yields:

$$
r c=c(Q, W)+\varepsilon+\mu
$$

\footnotetext{
${ }^{1}$ More details about DEA and stochastic frontier techniques, see Kalirajan \& Shand (1999).
} 
In the equation above, $\varepsilon$ is a term of random error; and other variables in lowercase are logarithmic form of the corresponding variables in equation (4).

We should define the inputs and outputs definitely as regard to equation (4) in precedence of conducting regression estimation. In equation (4), price vector takes average cost of loanable funds and average price of operation inputs as its components. As to average cost of loanable funds, it is defined as the ratio between the sum of commission charged and interest expenditure on bank's liability and average quantity of loanable funds, while the average price of operation inputs is taken as the ratio of operation expenses and average total assets. We take the ratio of operating expenses as a proportion of average total assets as the average price of operation inputs. And Bank's outputs are defined as total loans, amount of investment and non-interest proceeds. Finally, for availability of data, we just include three typical items as constituents of total real cost of a bank, which are commission free charged, interest expenditure and operation expenses respectively.

Then we estimate cost efficiency of individual banks with the following formula (Jondrow et al (1982)):

$$
\hat{u}_{i}=E\left(u_{i} \mid \hat{e}_{i}\right)=\frac{\sigma \lambda}{1+\lambda^{2}}\left(\frac{\phi\left(\lambda \hat{e}_{i}\right)}{\Phi\left(\lambda \hat{e}_{i}\right)}+\lambda \hat{e}_{i}\right)
$$

$\hat{u}_{i}$ denotes inefficiency term of a bank, and $e_{i}$ represents residual of regression; $\phi(\cdot)$ and $\Phi(\cdot)$ are, respectively, the density and distribution functions of a standardized normal random variable.

\section{$B$ Index for Inefficiency of Regional Banking System}

We then use a weighted average to construct an index for inefficiency of regional banking system in which weights are the proportion of loans by a specific bank for a region in total loans issued in that region. The data for the loans of each bank at each region is mostly extracted from "Year Book of Chinese Finance”. For some relatively small-sized commercial banks, the Year Book does not give regional data; we then create the regional data through multiplying total loans of that bank for one year by the proportion of regional GDP in the GDP of the whole nation.

The index we propose for the inefficiency of banking system for each region is therefore defined as follows:

$$
\hat{\mu}_{j t}=\sum a_{i j t} \hat{u}_{i t(t+1)}
$$

$\hat{\mu}_{j t}$ denotes the value of the inefficiency for banking system of region $j$. And $\hat{u}_{i t(t+1)}$ represents the value of inefficiency for bank $i$ from year $t$ to $t+1 ; \alpha_{i j t}$ is the ratio between loans of bank $i$ issued in region $j$ and total loans region $j$ received in year $t$. Table 1 gives the results estimated for the value of inefficiency of banking system for each region in China.
Table 1: Value of inefficiency of banking system for various

\begin{tabular}{|c|c|c|c|c|c|c|}
\hline & 2004 & 2005 & 2006 & 2007 & 2008 & 2009 \\
\hline Beijing & 7.1 & 5.77 & 6.3 & 5.31 & 4.63 & 4.53 \\
\hline Tianjing & 6.75 & 6.9 & 8.1 & 6.21 & 6.23 & 6.83 \\
\hline Hebei & 6.93 & 7.48 & 7.82 & 6.12 & 6.54 & 6.67 \\
\hline Shanxi & 6.94 & 8.02 & 7.63 & 5.86 & 6.7 & 6.72 \\
\hline Neimenggu & 6.67 & 7.69 & 7.07 & 5.26 & 6.19 & 6.07 \\
\hline Liaoling & 7.01 & 7.67 & 7.71 & 6.31 & 6.57 & 6.83 \\
\hline Jiling & 7.03 & 7.65 & 8.11 & 6.28 & 6.26 & 6.24 \\
\hline Heilongjiang & 6.93 & 7.62 & 7.79 & 6.26 & 6.78 & 6.71 \\
\hline Shanghai & 5.59 & 5.6 & 6.4 & 5.43 & 4.91 & 4.74 \\
\hline Jiangsu & 6.23 & 5.83 & 6.86 & 5.68 & 5.46 & 5.51 \\
\hline Zhejiang & 6.12 & 6.36 & 6.44 & 5.42 & 5.38 & 5.1 \\
\hline Anhui & 6.76 & 7.72 & 7.73 & 6.25 & 6.64 & 7.27 \\
\hline Fujian & 7.62 & 6.69 & 7.56 & 5.65 & 5.51 & 6.34 \\
\hline Jiangxi & 7.96 & 7.79 & 7.83 & 5.96 & 6.34 & 6.25 \\
\hline Shandong & 7.08 & 7.24 & 8.62 & 6.54 & 6.05 & 5.81 \\
\hline Henan & 6.72 & 7.55 & 8.31 & 6.94 & 7.38 & 7.73 \\
\hline Hunan & 6.96 & 7.24 & 8.82 & 6.83 & 6.44 & 6.78 \\
\hline Hubei & 7.14 & 7.14 & 8.25 & 6.68 & 6.93 & 7.49 \\
\hline Guangdong & 6.73 & 5.81 & 6.36 & 4.46 & 4.73 & 4.98 \\
\hline Guangxi & 6.77 & 7.4 & 7.76 & 6.34 & 7.05 & 7.42 \\
\hline Hainan & 7.26 & 6.62 & 10.97 & 9.25 & 7.69 & 7.81 \\
\hline Sichang & 7.03 & 7.04 & 8.33 & 6.22 & 7.19 & 7.25 \\
\hline Guizhou & 7.53 & 8.6 & 7.71 & 5.96 & 7.55 & 7.91 \\
\hline Yunnan & 7.02 & 7.69 & 7.32 & 6.16 & 7.38 & 7.87 \\
\hline Xizang & 7.87 & 7.79 & 6.83 & 5.42 & 8.36 & 8.74 \\
\hline Shanxi & 7.84 & 8.53 & 8.3 & 6.9 & 7.49 & 7.86 \\
\hline Gansu & 7.31 & 8.03 & 7.18 & 5.85 & 7.13 & 7.82 \\
\hline Qinghai & 7.42 & 8.32 & 7.35 & 5.67 & 7 & 7.18 \\
\hline Ningxia & 7.35 & 8.03 & 7.57 & 5.88 & 6.83 & 6.76 \\
\hline Xinjiang & 7.67 & 8.4 & 8.09 & 6.61 & 7.55 & 7.75 \\
\hline Chongqing & 6.86 & 7.59 & 7.16 & 5.36 & 6.8 & 6.83 \\
\hline
\end{tabular}
regions(percentage)

We can reach some conclusions from table 1: Firstly, on average, during the former half period of 2004-2009, the efficiency of banking system for every region is quite low, while in the latter half period the value of efficiency is high, which discloses that a series of reform in banking sector recently launched begin to show its effects. Secondly, in the fastest growing regions, such as Beijing, Shanghai, Guangdong Province, etc, its efficiency of banking system is higher, while in Hubei, Guangxi, Hunan Provinces, etc, whose growth rate is relatively lower, its banking system's efficiency is lower too.

\section{Growth Regressions}

\section{A The equation for regression}

The equation is established for the regression based on equation (3):

$$
y_{i t}=\alpha+\hat{\varphi} y_{i(t-1)}+\chi k_{i(t-1)}+\hat{\rho} \ln \left(1-\hat{\mu}_{i(t-1)}\right)+\Psi S_{i(t-1)}+\eta_{i}+\varepsilon_{i t}
$$

In this formula, $\varphi$ is a key variable, and $\hat{\varphi}=\varphi+1$. Only when the estimated value of $\hat{\varphi}$ is significantly less than one, 
does exist conditional convergence in the process of economic growth. $\chi$ and $\stackrel{\Lambda}{\rho}$ are the same as the counterpart coefficients of equation (3). As it is mentioned in part 2, if $\rho$ is significantly positive, then the banking system's effect of credit allocation on economic growth will occur. $\varepsilon_{i t}$ is residual term. $y_{i t}$ is the logarithm of GDP per capita of $i$ th region in the $t$ th year. $k_{i t}$ is the logarithm of ratio between total loans received by $i$ th region and GDP of that region in $t$ th year. $\hat{\mu}_{i t}$ is the value of inefficiency of banking system for $i$ th region and $t$ th year. Table 1 lists the value of banking system's inefficiency for all the regions in China from 2004 to 2009. $S_{n}$ is a vector containing various other variables, which have impacts on the steady state growth rate of a region. In this paper, PRIV, CENT, HUM, TRADE, and LAW are chosen as the components of vector $S_{n}$. PRIV is used to denote the ratio of credit granted to the private sector in a region as a proportion of total loans issued by that region, in an attempt to understand the influence of private sector's development on regional growth rate. CENT is the proportion of non-stateowned commercial banks' issued loans in the total loans granted by the whole banking system in a specific region, which to some extent reflects the ownership structure of regional banking system. As a proxy for human capital, HUM is defined as the proportion of the population aged from 15 to 64 enrolled in middle schools and in higher education. TRADE is the proportion of total value of imports and exports in regional GDP, depicting the economic openness of that region. Finally yet importantly, LAW is the ratio of closed cases against total cases received by the regional courts to indicate the efficiency of the regional judicial system.

The data for the above-mentioned variables are all extracted from selective issues of "Chinese Year Book", "Year Book of Chinese Finance" and various regional statistic yearbooks. The data about judicial cases are obtained from regional court yearbooks. The time span of the sample ranges from 2004 to 2009. All the variables in the regression equation are logarithmic.

Due to the limitation of the small-sized sample, GMM method is used to estimate equation (8) ${ }^{2}$, which is less demanding for the size of sample.

\section{B Estimation results}

Table 2: Main results of empirical analysis (T-statistics in parenthesis)

\begin{tabular}{|c|cccccccc|}
\hline & One & Two & Three & Four & Five & Six & Seven & Eight \\
\hline \multirow{2}{*}{ Constant } & 0.0712 & 0.0731 & 0.0844 & 0.0651 & 0.0795 & 0.0587 & 0.00981 & 0.0361 \\
& $(5.42)$ & $(4.93)$ & $(8.85)$ & $(3.85)$ & $(5.7)$ & $(4.59)$ & $(1.88)$ & $(2.94)$ \\
Y(-1) & 1.405 & 0.961 & 0.968 & 0.954 & 0.899 & 0.385 & 0.947 & 0.940 \\
& $(2.67)$ & $(2.25)$ & $(2.81)$ & $(3.48)$ & $(2.31)$ & $(0.56)$ & $(1.97)$ & $(3.96)$ \\
$\mathrm{k}$ & -0.0411 & 0.0725 & 0.0417 & -0.0254 & 0.0529 & 0.0465 & 0.0313 & 0.0483 \\
& $(2.54)$ & $(2.68)$ & $(2.74)$ & $(-0.412)$ & $(1.99)$ & $(3.95)$ & $(1.91)$ & $(4.38)$ \\
Ln(1-u) & 0.0159 & 0.0751 & & 0.0615 & 0.0496 & 0.0487 & 0.0625 & 0.0512 \\
Ln(PRIV & $(-0.64)$ & $(-4.67)$ & & $(2.67)$ & $(6.65)$ & $(-1.61)$ & $(5.22)$ & $(-3.41)$ \\
& & 0.0621 & 0.0881 & & 0.217 & 0.0991 & 0.0865 & 0.0899 \\
\hline
\end{tabular}

\footnotetext{
${ }^{2}$ See Gaselli et al (1996).
}

\begin{tabular}{|c|c|c|c|c|c|c|c|c|}
\hline ) & & (7.57) & (12.28) & & $(-5.45)$ & $(4.76)$ & $(7.12)$ & (4.99) \\
\hline Ln(CEN & & 0.410 & 0.0896 & 0.119 & & 0.0831 & 0.0983 & 0.0769 \\
\hline & & (3.56) & (2.53) & (1.99) & & (2.51) & $(1.75)$ & (3.95) \\
\hline Ln(HUM & & 0.0151 & 0.0267 & 0.0247 & 0.0276 & & 0.0315 & 0.033 \\
\hline ) & & (6.50) & (5.62) & (6.38) & (7.57) & & (5.98) & (6.73) \\
\hline Ln(TRA & & -0.0254 & $4-0.0615$ & -0.0315 & -0.0289 & -0.0551 & & -0.0387 \\
\hline DE) & & (1.99) & (2.37) & (2.88) & (2.27) & (3.69) & & (3.19) \\
\hline Ln(LAW & & 0.00714 & 40.01915 & 0.00121 & 0.00555 & 0.0193 & 0.0112 & \\
\hline ) & & $(2.75)$ & (1.89) & (2.183) & $(1.74)$ & (3.28) & (2.099) & \\
\hline $\begin{array}{l}\text { Adjusted } \\
\text { R-Square }\end{array}$ & 0.267 & 0.561 & 0.354 & 0.517 & 0.521 & 0.498 & 0.365 & 0.589 \\
\hline
\end{tabular}

Table 2 gives the results of estimation. In regression one, the coefficient of $y(-1)$, i.e. the value of $\stackrel{\Lambda}{\varphi}$ is significantly larger than 1 , which means that if just including two variables, namely, $k$ and inefficiency of banking system into equation (8), the variation of growth rate for all the regions will tend to increase, and the phenomenon of so-called "absolute divergence" will appear. In addition, the coefficient of $k$ is significantly negative, which is inconsistent with theoretical supposition. The coefficient of inefficiency term is negative, coinciding with our prediction; however, it is not significant.

From regression two to eight, in most cases, the value of $\hat{\varphi}$ is significantly less than 1 . Therefore, after adding variables into growth equation, such as human capital, etc, which have impact on steady state growth rate, the economic growth of all the regions in China shows obvious characteristics of "conditional convergence". Besides, the coefficient of $k$ is positive in all regressions except for regression four, indicating that for a specific region, keeping other variables constant, the larger the ratio of loans for that region and its GDP, the higher its growth rate. In central and western regions of China, whose growth rate is relatively lower, the economic growth is mainly pushed by investment with the result of comparatively larger ratio of banks' loans and GDP than other regions, while in fast growing eastern coastal areas, non-stateowned economy and outward oriented economy constitute the main contributors to economic growth, and the ratio of loans as a proportion of regional GDP is relatively low as a result. Therefore, it seems that the ratio between the amount of credit and GDP is negatively correlated with growth rate. But when controlling the effects of some variables, for instance, openness of economy, human capital, etc, the real impact of banking system's credit on economic growth is indeed positive. This may help explain the huge discrepancy between the estimated coefficent on $k$ in regression one and coefficent of $k$ in most other regressions. It should be noticed that nearly all regressions get to a statistically significant and positive coefficient of $\ln (1-\hat{u})$. This coincides with theoretical prediction in this paper: the efficiency of credit allocation of banking system has positive impact on regional economic growth. Therefore, our empirical evidence here demonstrates, at least in China, the existence of not only effect of capital accumulation of banking system, as widely accepted in the literature, but also its effect of credit allocation, which stresses the growth-stimulating role of banks' ability to screen borrowers and allocate credit optimally. 
Secondly, comparing the results of regression two and three, we find that the fitness of regression has been greatly improved, if taking the inefficiency term into growth equation. We can conclude that the impact of efficiency of banking system on regional economic growth is at least nonnegligible in this respect.

Finally, we look into the impact of other financial, control variables on economic growth. In light of Table 2, we find that, in China, human capital and non-state-owned economy all exert strong and positive influence on regional growth, i.e. the bigger the stock of human capital in a region and the proportion of the loans granted to the private economy, the higher is the economic growth rate for that region. Moreover, the coefficient of $\ln (C E N T)$ is positive, showing that the structure of banking system can also do with regional economic growth. To be specific, the bigger the proportion of loans issued by middle-sized non-state-owned banks in total loans for a region, the faster that region grows. A recent research by Chi guotai, Sun xiufeng and Lu dan(2005) shows that, in China, the average efficiency of non-state-owned banks outweighs that of 4 big state-owned banks. So, the conclusions reached here indirectly demonstrate that higher efficiency of banking system indeed does good to economic growth. It should be mentioned that the efficiency of judicial system saliently affects regional growth, and the estimated coefficient of $\ln (L A W)$ is significant in most cases. In regression eight, the fitness of regression is improved greatly instead, after excluding this variable. This could mainly be expounded by the facts that, in China, the efficiency of judicial system and the arrangement of it differ little across regions. In addition, the estimated coefficient of $\ln (T R A D E)$ is negative, in contrary to extant theories' prediction, and further explanations are needed, which are not included in this paper.

\section{The Conclusion}

The research in this paper empirically investigates the impact of banks' ability in optimizing credit allocation on
China's regional growth rate. The conclusion is that, in respect to the role of facilitating the economic growth, the banking system of China not only has the capital accumulation effect, but also demonstrates the credit allocation effect. In addition, we find that in regions where law enforcement is more efficient, the effect of banking system on economic growth is more salient.

Note:

This paper is an updated version of our previous working paper.

\section{References}

[1] Altunbas, Y., Gardener, E., and Moore, B. (2001). Efficiency in European Banking. European Economic Review, 45, 1931-1955.

[2] Berger, G. N. (1993). The efficiency of financial institutions: a review and preview of research past, present and future. Journal of Banking and Finance, 17, 221-249.

[3] Caselli, F., Esquivel, G. and Lefort, F. (1996). Reopening the convergence debate: A new look at cross-country growth empirics. Journal of Economic Growth, 1, 363-89.

[4] Chi guotai, Sun xiufeng and Lu dan(2005). The empirical investigation into the cost efficiency of commercial banks in China. The Economic Research Journal, issue 6.

[5] Diamond, D. (1984). Financial intermediation as delegated monitoring. Review of Economic Studies, 51, 647-63.

[6] Ferri, G. and Mattesini, F. (1997). Finance, human capital and infrastructure: an empirical investigation of post-war Italian growth. Banca d'Italia, Temi di Discussione, 321.

[7] Goldsmith, R. (1969). Financial Structure and Development. New Haven.

[8] Islam, N. (1995). Growth empirics: A panel data approach. Quarterly Journal of Economics, 110, 4, pp. 1127-70.

[9] Jondrow, J., Lovell, C., and Schmidt, P. (1982). On the estimation of technical inefficiency in the stochastic frontier production function model. Journal of Econometrics, 19, pp.233-38.

[10] Kalirajan, K. and Shand, R. (1999). Frontier production functions and technical efficiency measures. Journal of Economic Surveys, 13, pp. 149-72. 